\title{
CARBOXYLATE SUBSTITUTION PATTERN AS STRUCTURAL DIRECTIVE FOR THE FINAL PRODUCTS: SYNTHESIS, STRUCTURE AND PROPERTIES OF $\left[\mathrm{Fe}_{4} \mathrm{Ca}_{2} \mathrm{O}_{2}\left(\mu_{2}-\mathrm{HCCl}_{2} \mathrm{COO}\right)_{10}\left(\mu_{3}-\mathrm{HCCl}_{2} \mathrm{COO}\right)_{2}(\mathrm{THF})_{6}\right]$
}

\author{
Denis Prodiuss, Valeriu Mereacre ${ }^{\mathrm{a}}$, Maria Gdaniec ${ }^{\mathrm{b}}$, Sergiu Shova ${ }^{\mathrm{c}, \mathrm{g}}$, Yurii A. Simonov ${ }^{\mathrm{c}}$, Nicolae \\ Stanica ${ }^{\mathrm{d}}$, Ion Geru ${ }^{\mathrm{e}}$, Andrea Caneschi ${ }^{\mathrm{f}}$, Constantin Turta ${ }^{\mathrm{a} *}$ \\ ${ }^{a}$ Institute of Chemistry of the Academy of Sciences of Moldova, 3 Academy str., MD-2028, Chisinau, Moldova \\ ${ }^{b}$ Faculty of Chemistry, A.Mickiewicz University, Poznan, Poland \\ "Institute of Applied Physics, Academy of Sciences of Moldova, Chisinau, Moldova \\ 'Institute of Physical Chemistry "Murgulescu”, Romanian Academy, Bucharest, Romania \\ ${ }^{e}$ The Metrology and Analytical Methods of Research Center, Academy of Sciences of Moldova, Chisinau, Moldova \\ ${ }^{f}$ Department of Chemistry and INSTM Research Unit, University of Florence, Florence, Italy \\ ${ }^{g}$ Department of Chemistry, State University of Moldova, Chisinau, Moldova \\ *Fax: (373 22) 739954; Tel: (373 22) 739755; E-mail: turtac@yahoo.com
}

\begin{abstract}
A novel hexanuclear iron-calcium-oxo complex has been synthesized and characterized by different physicochemical methods and X-ray single crystal structural analysis: $\left[\mathrm{Fe}_{4} \mathrm{Ca}_{2} \mathrm{O}_{2}\left(\mu_{2}-\mathrm{HCCl}_{2} \mathrm{COO}\right)_{10}\left(\mu_{3}-\mathrm{HCCl}_{2} \mathrm{COO}\right)_{2}(\mathrm{THF})_{6}\right]$. The molecular structure shows that there are two types of coordination for $\mathrm{COO}^{-}$anions: bidentate and tridentate. The corresponding variable temperature susceptibility measurement shows that in the complex there exists an antiferromagnetic interaction $\left(\left|\mathrm{J}_{12}\right|=\left|\mathrm{J}_{34}\right|=-71.86 \mathrm{~cm}^{-1}\right)$. The iron(III) high spin state (5/2) is proved by Mössbauer spectroscopy. High magnetic EPR measurements of 1 indicates the presence of $S=0$ ground state with low-lying $S=1$ excited state centred around $g=2.0054 \pm 0.0001$.
\end{abstract}

Keywords: Iron(III) calcium(II) heterocluster; crystal structure; antiferromagnetic interaction.

\section{Introduction}

Polynuclear carboxylates of $3 \mathrm{~d}$ transition metals have been attracting renewed interest because of their intramolecular magnetic exchange interactions $[1,2]$ and their application as the simple models of oligonuclear active sites in metalloproteins [3-6]. The unambiguous attribution of the individual site in the trimer to one or another metal in these complexes is impeded by at least two factors: $i$ ) the close atomic numbers of the $\mathrm{Fe}$ and $\mathrm{M}$ metals and ii) the statistical distribution of the clusters in the crystal structure. The extensive investigations of other complexes with dichloroacetic acid have been reported [7-9]. However the information about $\left\{\mathrm{M}_{3} \mathrm{O}\right\}$ core containing bivalent metal that does not belong to $3 \mathrm{~d}$ elements, proved by X-ray crystallography is still absent.

Here we presnt a novel hexanuclear iron-calcium-oxo complex $\left[\mathrm{Fe}_{4} \mathrm{Ca}_{2} \mathrm{O}_{2}\left(\mu_{2}-\mathrm{HCCl}_{2} \mathrm{COO}\right)_{10}\left(\mu_{3}-\right.\right.$ $\left.\left.\mathrm{HCCl}_{2} \mathrm{COO}\right)_{2}(\mathrm{THF})_{6}\right](\mathbf{1})$ which is aggregated from two $\mu_{3}$-oxo fragments. The detailed crystal structure and magnetic property were discussed.

\section{Results and discussion}

$\mathrm{X}$-ray diffraction revealed that crystal 1 at $293 \mathrm{~K}$ has a molecular structure consisted of neutral complexes, the charge balance of which is in agreement with formation of $\left[\mathrm{Fe}_{4} \mathrm{Ca}_{2} \mathrm{O}_{2}\left(\mu_{2}-\mathrm{HCCl}_{2} \mathrm{COO}\right)_{10}\left(\mu_{3}-\mathrm{HCCl}_{2} \mathrm{COO}\right)_{2}(\mathrm{THF})_{6}\right]$ species. Molecular structure of 1 at $293 \mathrm{~K}$ is depicted in figure 1. Two $\mathrm{Ca}^{2+}$ and four $\mathrm{Fe}^{3+}$ metal ions are associated into hexanuclear cluster through two $\mu_{3}$-oxo atoms (Ca1-O1 2.417(3), Fe1-O1 1.840(1), Fe2-O(1) 1.827(1) ( $\AA$ ) for 293 K; Ca1-O1 2.410(3), Fe1-O1 1.833(3), Fe2-O(1) 1.831(3) ( $\AA$ ), average values for A and B independent complexes at $130 \mathrm{~K}$ ) and twelve dichloroacetate ligands. Ten carboxylates act as $\eta^{1}: \eta^{1}: \mu$ bidentate bridging units while two others as bridging tridentate $\eta^{1}: \eta^{2}: \mu$ units. The molecular structure of $\mathbf{1}$ could be described as a combination of two centrosymmetrically related trinuclear $\left[\mathrm{Fe}_{2} \mathrm{CaO}\left(\mathrm{CHCl}_{2} \mathrm{COO}\right)_{6}(\mathrm{THF})_{3}\right]$ entities, which closely resemble published $\left[\mathrm{Fe}_{2} \mathrm{CaO}\left(\mathrm{CHCl}_{2} \mathrm{COO}\right)_{6}(\mathrm{THF})_{4}\right][10]$. The metal $\cdots$ metal separation within the $\left\{\mathrm{Fe}_{4} \mathrm{Ca}_{2}\left(\mu_{3}-\mathrm{O}\right)_{2}\right\}$ core exhibits the following values: $\mathrm{Ca} 1 \cdots \mathrm{Fe} 13.635(2), \mathrm{Ca} 1 \cdots \mathrm{Fe} 23.704(2), \mathrm{Fe} 1 \cdots \mathrm{Fe} 2$ 3.204(2), $\mathrm{Ca} 1 \cdots \mathrm{Ca} 1$ ' 3.957(2) ( $\AA$ ) for 293 $\mathrm{K}$; $\mathrm{Ca} 1 \cdots \mathrm{Fe} 1$ 3.632(2), $\mathrm{Ca} 1 \cdots \mathrm{Fe} 2$ 3.676(2), $\mathrm{Fe} 1 \cdots \mathrm{Fe} 2$ 3.203(2), $\mathrm{Ca} 1 \cdots \mathrm{Ca} 1{ }^{\prime} 3.918(2)$ ( $\AA$ ) in average for A and B independent complexes at $130 \mathrm{~K}$. Each $\mathrm{Fe}^{3+}$ ions has a similar octahedral coordination completed by six oxygen atoms: four from bidentate bridging carboxylate groups in equatorial plane; two another from THF molecule and $\mu_{3}-\mathrm{O}$ in apical position. The coordination number of $\mathrm{Ca}^{2+}$ ion reaches the value 8 due to the coordination of the oxygen atom $(\mathrm{Ca} 1-\mathrm{O} 22.450(3) \AA$ for $293 \mathrm{~K} ; 2.457(3) \AA$ for $130 \mathrm{~K})$ from tridentate $\eta^{1}: \eta^{2}: \mu$ carboxylate unit.

$\mathrm{X}$-ray single crystal structural study at 293 and $130 \mathrm{~K}$ has demonstrated that compound $\mathbf{1}$ exhibits a structural 
phase transition in this temperature range. In the frame of the same space group $(\mathrm{P} \overline{1})$, the lowering of the temperature from 293 to $130 \mathrm{~K}$ leads to the doubling of the unit cell volume with two crystallographic independent molecules. The molecular structures of two complexes at $130 \mathrm{~K}$ are quite similar and slightly differ only by the orientation of the THF ligands coordinated to $\mathrm{Ca}$ atoms.

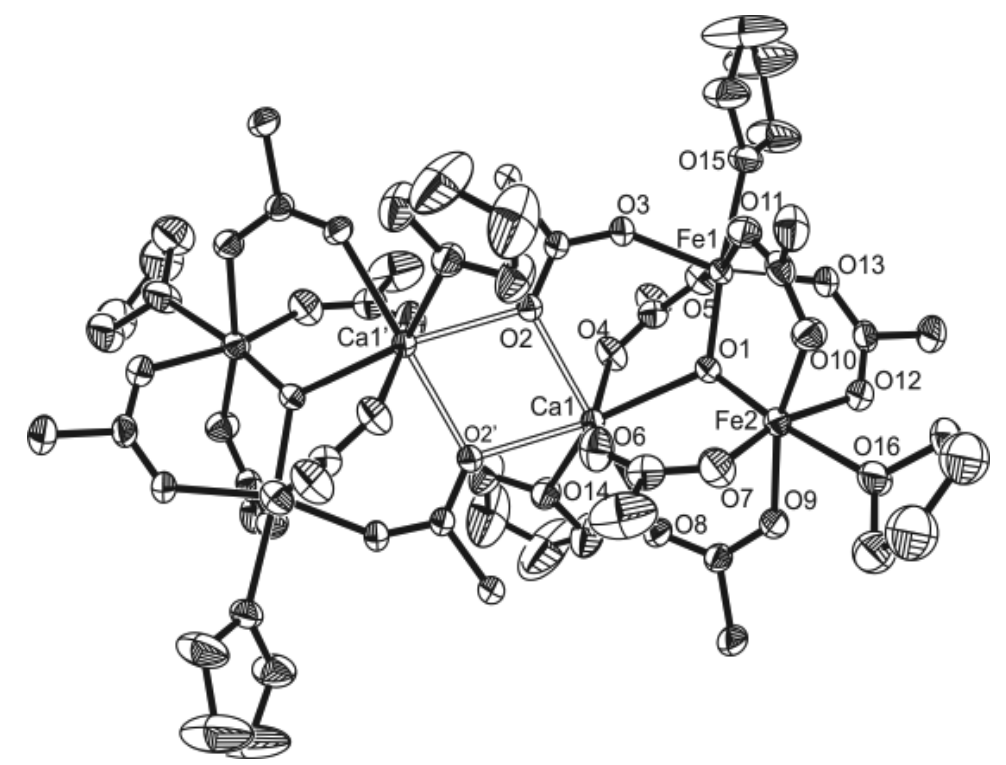

Fig. 1. Molecular structure of $\left[\mathrm{Fe}_{4} \mathrm{Ca}_{2}\left(\mu_{3}-\mathrm{O}\right)_{2}\left(\mathrm{CHCl}_{2} \mathrm{COO}\right)_{12}(\mathrm{THF})_{6}\right]$ at $293 \mathrm{~K}$. Chlorine atoms are omitted for clarity. The thermal ellipsoids are drawn at the $40 \%$ probability level.

The thermal decomposition of $\mathbf{1}$ in air is a multistage process. The elimination of THF molecules starts at $50^{\circ} \mathrm{C}$. The first endothermic process is characterized by a maximum at $\sim 70^{\circ} \mathrm{C}$ and it ends at $\sim 80{ }^{\circ} \mathrm{C}$ with $\sim 6.5$ mass loss, which corresponds to the elimination of two THF molecules per formula unit from of the crystal. The second endothermic process showed the maximum at $220^{\circ} \mathrm{C}$ on the DTG curve. The total mass loss in these processes is $\sim 68 \%$ that corresponds to removal of all THF molecules and partial decomposition of the dichloroacetate groups. An unexpected endothermal process has been observed in the range $410-455^{\circ} \mathrm{C}$. The peak registered was not accompanied by any mass change. Probably, it results from a phase transition of the reaction product. However, this statement requires additional confirmation. According to DTG data, the residual sample after decomposition consists in about $\sim 19 \%$ of the initial sample mass and most probably corresponds to $\mathrm{CaO} \cdot \mathrm{Fe}_{2} \mathrm{O}_{3}$.

The Mossbauer spectrum (MS) of $\mathbf{1}$ was measured at $295 \mathrm{~K}$. The room temperature ${ }^{57} \mathrm{Fe}$ MS of 1 shows two symmetrical central absorption lines which were assigned to one doublet with the parameters: $\delta_{\mathrm{Fe}}=0.41 \mathrm{~mm} / \mathrm{s} ; \Delta \mathrm{E}_{\mathrm{Q}}=$ $0.53 \mathrm{~mm} / \mathrm{s}$. They indicate the presence of $\mathrm{Fe}(\mathrm{III})$ ions in the high spin state $(\mathrm{S}=5 / 2)$ with the rather symmetrical electron density distribution.

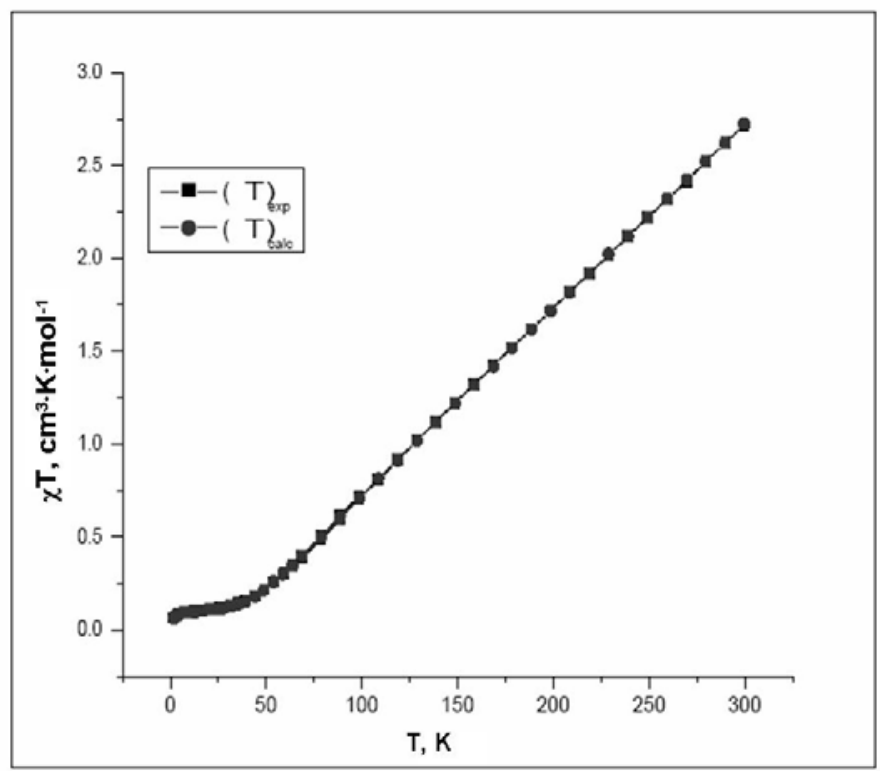

Fig.2. Plot of the $\chi_{M}$ T product of $\mathbf{1}$ as a function of temperature. The solid line is a fit of the experimental data to the HDVV model; see the text for the fitting parameters. 
The magnetic properties of compounds 1 has been measured in the range of temperatures $300-2.0 \mathrm{~K}$. The substance is characterized by a gradual reduction of the $\chi_{\mathrm{M}} \mathrm{T}$ product with the lowering of temperature (Fig. 2) thus indicating an antiferromagnetic interaction between the iron (III) ions. Lower than $\sim 30 \mathrm{~K}$ the plateau exists.

For interpretation of magnetic properties of 1 the HDVV model for $\mathrm{Fe}_{4}$ was used with the following scheme of interaction:

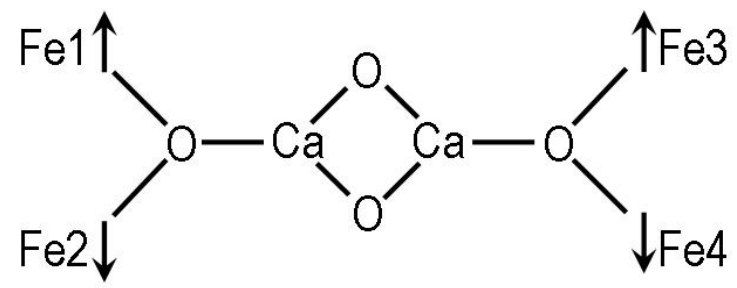

The original least-squares fitting computer program FDHM [11, 12] with a Full Diagonalisation of Hamiltonian Matrix approach was employed to fit $(\chi T)_{\text {exp. }}$ vs. T, in order to obtain the exchange couplings constants. The program uses the spin Hamiltonian operator:

$\mathbf{H}_{\text {total }}=\mathbf{H}_{H D V V}+\mathbf{H}_{Z}$

$\mathbf{H}_{H D V V}=-2 \mathbf{J}\left(\mathbf{S}_{F e 1} \mathbf{S}_{F e 2}+\mathbf{S}_{F e 3} \mathbf{S}_{F e 4}\right)-2 \mathbf{J}^{\prime}\left(\mathbf{S}_{F e 1} \mathbf{S}_{F e 3}+\mathbf{S}_{F e 2} \mathbf{S}_{F e 4}\right)-2 \mathbf{J}^{\prime \prime}\left(\mathbf{S}_{F e 1} \mathbf{S}_{F e 4}+\mathbf{S}_{F e 2} \mathbf{S}_{F e 3}\right)$

where $\mathbf{H}_{Z}=g \mu_{\mathrm{B}} \sum_{i=1}^{4} \mathbf{S}_{i}^{z} B$,

$\mathbf{S}_{i}=5 / 2$ is the spin operator of the $i$-th ion, $\mathrm{J}_{\mathrm{i}}$ are the exchange parameters, $\mu_{\mathrm{B}}$ is the Bohr magneton, $\mathrm{g}$ is the electronic $\mathrm{g}$-factor for the tetranuclear compound, B is the magnetic field strength. The magnetic susceptibility data of $\mathbf{1}$ was calculated from the spin-coupled wave function by using a simplified form of Van Vleck equation. The better fitting was obtained at the following values of exchange parameters: $\mathrm{J}=\mathrm{J}_{12}=\mathrm{J}_{34}=-71.86 \mathrm{~cm}^{-1} ; \mathrm{J}^{\prime}=\mathrm{J}_{13}=\mathrm{J}_{24}=+0.18 \mathrm{~cm}^{-1} ; \mathrm{J}^{\prime \prime}=\mathrm{J}_{14}$ $=\mathrm{J}_{23}=-2.46 \mathrm{~cm}^{-1}, \rho_{\text {paramagn. impur. }}=2.5 \%$ and $\theta_{\text {Curie Weiss }}=2.46 \mathrm{~K}$, and $\mathrm{F}_{\text {qualit. factor }}=1.46 \cdot 10^{-5}$.

High magnetic EPR measurements of 1 indicates the presence of $\mathrm{S}=0$ ground state with low-lying $\mathrm{S}=1$ excited state centred around $g=2.0054 \pm 0.0001$ (Fig.3). This result is in a good agreement with the above mentioned scheme of

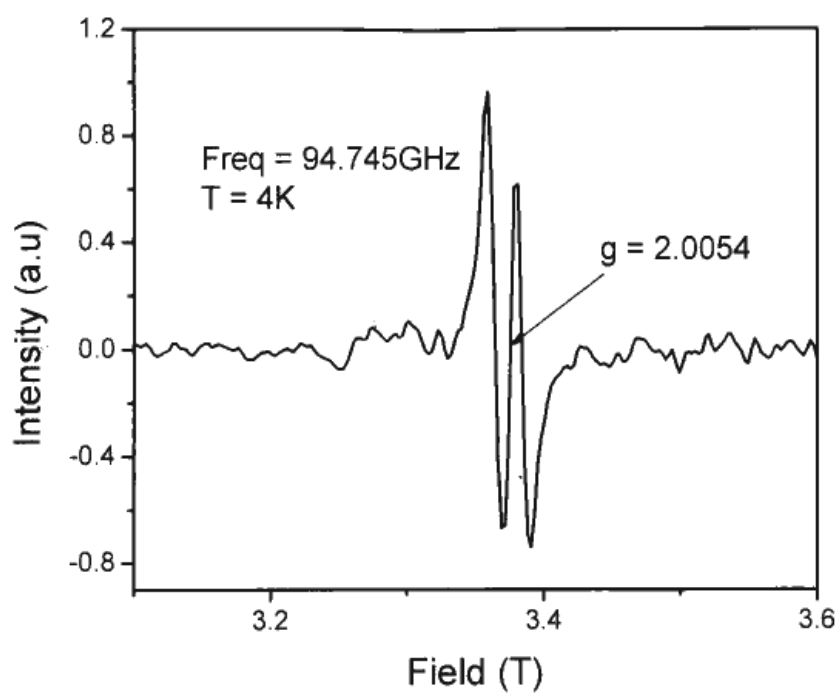

Fig. 3. W - band powder EPR spectrum of 1 at $4 \mathrm{~K}$.

exchange interactions leading to antiferromagnetic coupling between iron(III) ions in a high spin state: Fe1-Fe2 and $\mathrm{Fe} 3-\mathrm{Fe} 4$, respectively. As the individual iron(III) ions are in a high spin state $(\mathrm{S}=5 / 2)$ that has been shown by our investigations of the Mossbauer spectrum of 1, the existence of a ground state spin singlet for 1 is a simple consequence of $\mathbf{D}_{5 / 2} \otimes \mathbf{D}_{5 / 2}$ direct product of the rotation group representations

$\left(\mathbf{D}_{5 / 2} \otimes \mathbf{D}_{5 / 2}=\sum_{S=0}^{5} D_{s}\right)_{o}$

Here $\mathrm{D}_{\mathrm{o}}$ and $\mathrm{D}_{1}$ correspond to ground singlet spin state exited triplet spin state of dimmers $\mathrm{Fe} 1-\mathrm{Fe} 2$ and $\mathrm{Fe} 3-\mathrm{Fe} 4$ characterized by the same exchange integral $\left(\mathrm{J}=\mathrm{J}_{12}=\mathrm{J}_{34}=-71.86 \mathrm{~cm}^{-1}\right)$ according to magnetic susceptibility data. 


\section{Experimental}

Synthesis. The title compound was synthesised by the reaction of $\mathrm{Fe}\left(\mathrm{NO}_{3}\right)_{3} \cdot 9 \mathrm{H}_{2} \mathrm{O}$ with 2 equivalents of $\mathrm{Ca}\left(\mathrm{CHCl}_{2} \mathrm{COO}\right)_{2} \cdot 6 \mathrm{H}_{2} \mathrm{O}$ in methanol, followed by evaporation of solvent at room temperature [13]. Dissolving in tetrahydrofuran(THF) theobtainedsolidgivesared-orangesolution which crystals of $\left[\mathrm{Fe}_{4} \mathrm{Ca}_{2}\left(\mu_{3}-\mathrm{O}\right)_{2}\left(\mathrm{CHCl}_{2} \mathrm{COO}\right)_{12}(\mathrm{THF})_{6}\right]$ are obtained from. A brown-orange crystalline material has been separated after 2 weeks, washed with heptane and air dried. The yield is high ( 87\%). Calc. (Found) for $\mathrm{C}_{48} \mathrm{H}_{60} \mathrm{Cl}_{24} \mathrm{Fe}_{4} \mathrm{Ca}_{2} \mathrm{O}_{32}: \mathrm{C}, 25.03(24.94) ; \mathrm{H}, 2.63(2.47) ; \mathrm{Fe}, 9.70(9.92)$; $\mathrm{Ca}, 3.48(3.37) \%$.

The Mossbauer spectra were acquired using a constant acceleration spectrometer with symmetrical waveform. ${ }^{57} \mathrm{Co}(1.0 \mathrm{MBq})$ source at room temperature has been used.

Variable temperature susceptibility studies were recorded with an Oxford Instruments Vibrating Sample Magnetometer (VSM) working between 0 and $12 \mathrm{~T}$ and in the $1.5-350 \mathrm{~K}$ temperature range.

EPR measurements. Polycrystalline powder EPR spectra were recorded at frequencies ranging from $90-270 \mathrm{GHz}$ at the high-field electron magnetic resonance facility at the National High Magnetic Field Laboratory in Tallahassee (USA), as described elsewhere $[14,15]$. The sample's temperature was varied from 300 to $4 \mathrm{~K}$.

Crystal data for 1: $(130 \mathrm{~K}) \mathrm{C}_{48} \mathrm{H}_{60} \mathrm{Ca}_{2} \mathrm{Fe}_{4} \mathrm{Cl}_{24} \mathrm{O}_{32}, M_{\mathrm{r}}=2303.32$, triclinic, space group $\mathrm{P} \overline{1}, a=13.475(3)$, $b=14.678(3), c=24.152(5)(\AA), \alpha=84.99(3), \beta=79.21(3)^{\circ}, \gamma=63.57(3)\left({ }^{\circ}\right), \mathrm{V}=4202.0(15) \AA^{3}, Z=2$, $\rho_{\text {calcd }}=1.820 \mathrm{~g} / \mathrm{cm}^{3}, M_{\lambda}$ radiation $\left(\lambda=0.71073 \AA, \mu=1.639 \mathrm{~mm}^{-1}\right), R=0.0615\left(F^{2}>2 \sigma\right), R_{\mathrm{w}}=0.1518$ (for 14773 data and 994 refined parameters); $(293 \mathrm{~K}) \mathrm{C}_{48} \mathrm{H}_{60} \mathrm{Ca}_{2} \mathrm{Fe}_{4} \mathrm{Cl}_{24} \mathrm{O}_{32}, M_{\mathrm{r}}=2303.32$, triclinic, space group P $\overline{1}, a=$ 13.611(3), $b=14.919(3), c=12.784(3)(\AA), \alpha=81.28(3), \beta=69.73(3)^{\circ}, \gamma=63.55(3)\left(^{\circ}\right), \mathrm{V}=2180.0(8) \AA^{3}, Z=1$, $\rho_{\text {calc }}=1.754 \mathrm{~g} / \mathrm{cm}^{-3}, \operatorname{MoK}_{\lambda}$ radiation $\left(\lambda=0.71073 \AA, \mu=1.580 \mathrm{~mm}^{-1}\right), R=0.0618\left(F^{2}>2 \sigma\right), R_{\mathrm{w}}=0.1581$ (for 8532 data and 466 refined parameters).

X-ray diffraction data were collected with a Kuma KM4CCD diffractometer using graphite-monochromated Mo$K_{\alpha}$ radiation. The crystal was placed $60 \mathrm{~mm}$ from the CCD detector. For both temperatures, more than hemisphere of reciprocal space was covered by combination of six sets of exposures; each set had a different $\varphi$-angle $(0,90,180,270$, 45,135 ) and each exposure of $30 \mathrm{~s}$ covered $0.75^{\circ}$ in $\omega$. Coverage of the unique set is $99.2 \%$ complete up to $2 \Theta=52^{\circ}$. The unit cell determination and data integration were carried out using the CrysAlis package of Oxford Diffraction. Intensity data were corrected for the Lorentz and polarization effects. The structure was solved by direct methods and refined with the SHELX program by full-matrix least-squares techniques. Non-hydrogen atoms were refined with anisotropic displacement parameters. $\mathrm{H}$ atoms were placed at calculated positions and refined as riding atoms in the subsequent least squares model refinements. For better fitting of the electron density, the positions of some of the $-\mathrm{CHCl}_{2}$ groups and one THF ligand were refined taking into account disordered models in the combination with the available tools (PART, DFIX and SADI) in SHELXL97 [16, 17]. The atoms belonging to the minor component of the disordered fragment were refined only isotropically. CCDC 692342 (130 K), CCDC 692959 (293 K) contain the supplementary crystallographic data for this structure. These data can be obtained free of charge via www.ccdc.cam.ac.uk/conts/retrieving.html (or from the Cambridge CB21EZ, UK; fax: (+44) 1223-336-033; or deposit@,ccdc.cam.ac.uk

\section{Conclusions}

In conclusion the technique of synthesis of new hexanuclear bis $\left(\mu_{3}\right.$-oxo $)$ carboxylates containing $\left\{\mathrm{Fe}_{4} \mathrm{Ca}_{2} \mathrm{O}_{2}\right\}$ core is developed. Mossbauer spectrum of this complex at room temperature shows one doublet characteristic for $\mathrm{Fe}(\mathrm{III})$ positions in a high spin state $(\mathrm{S}=5 / 2)$. In the range of temperature $300-20 \mathrm{~K}$ between iron (III) ions there is an antiferromagnetic exchange interaction in the two isosceles triangular skeletons with the following values of exchange integral $\left(\mathrm{J}=\mathrm{J}_{12}=\mathrm{J}_{34}=-71.86 \mathrm{~cm}^{-1}\right)$. High magnetic EPR measurements of $\mathbf{1}$ indicates the presence of $\mathrm{S}=0$ ground state with low-lying $\mathrm{S}=1$ excited state centred around $\mathrm{g}=2.0054 \pm 0.0001$.

\section{Supporting information available.}

Listing crystallographic parameters in CIF format, atomic coordinates, bond distances and angles, thermal parameters and hydrogen atom positions for the title complex are available free of charge from authors.

\section{Acknowledgements}

We thank the MRDA-CRDF (BGP III-\# MOP2-3061-CS-03; MTFP-017/05) and CSSDT (\#08.819.05.01F) for partial funding of this work, Dr. S. Nellutla for technical assistance at EPR measurements and Prof. N.S. Dalal for helpful discussion of EPR results.

\section{References}

[1] Kahn, O. Molecular Magnetism; VCH Publishers Inc.: New York, USA, 1993, p. 225;

[2] Turnbull, M. M.; Sugimoto,T.; Thompson, L. K. Molecule-based Magnetic Materials, ACS Symposium Series, USA, 1996, p. 314;

[3] Davis, C. M.; Royer, A. C.; Vincent, J. B. Inorg. Chem. 1997, 36, 5316-5320;

[4] Fontecave, M.; Menage, S.; Doboe-Toia, C. Coord. Chem. Rev. 1998, 178-180, 1555-1572;

[5] Bois, J. D.; Mizoguchi, T. J.; Lippard, S. J. Coord. Chem. Rev. 2000, 200-202, 443-485; 
[6] Ruettinger, W.E.; Dismukes,G.C. Inorg. Chem. 2000, 39, 1021-1027.

[7] Jinkwon, K.; Jin Mook, L.; Youngkyu, D. Eur. J. Inorg. Chem. 2003, 14, 2563;

[8] Soler, M.; Chandra, S.K.; Davidson, E.R.; Christou, G.; Ruiz, D.; Hendrickson, D.N. Chem.Comm. 2000, 24, 2417;

[9] Soler, M.; Chandra, S.K.; Ruiz, D.; Huffman, J.C.; Hendrickson, D.N.; Christou, G. Polyhedron 2001, 20, 12791283;

[10] Turta, C.; Shova, S.; Prodius, D.; Mereacre, V.; Gdaniec, M.; Simonov Yu. "Abstracts of the XXI-th International Chugaev Conference on Coordination Chemistry”, Kiev, Ukraine, 2003, p.183;

[11] Stanica, N. Ph.D. Thesis, Romanian Academy, Institute of Physical Chemistry, 1997;

[12] Stanica, N.; Lepadatu, C.; Jitaru, I. Revue Roumaine de Chimie 1998, 43(5), 433-437;

[13] Prodius, D.; Turta, C.; Mereacre, V.; Shova, S.; Gdaniec, M.; Simonov Y.; Lipkowski, J.; Kuncser, V.; Filoti, G.; Caneschi, A. Polyhedron 2006, 25, 2175-2182;

[14] Cage, B.; Hassan, A. K.; Pardi, L.; Krzystek, J.; Brunel, L. C.; Dalal, N. S. J. Magn. Res. 1997, 124, 495-498;

[15] Hassan, A. K.; Pardi, L.; Krzystek, J.; Sienkiewicz, A.; Goy, P.; Rohrer, M.; Brunel, L. C. J. Magn. Res. 2000, 142, 300-312;

[16] Otwinowski, Z; ; Minor, W. Processing of X-ray Diffraction Data Collected in Oscillation Mode, in Methods in Enzymology, Macromolecular Crystallography, Part A, edited by C.W. Carter \& R.M. Sweet, New York: Academic Press, 1997, 276, 307;

[17] Sheldrick, G.M. SHELX-97, Göttingen (Germany), Univ. of Göttingen, 1997. 